PALABRAS DEL CANCILLER FEDERAL, HELMUT KOHL, CON OCASIÓN DEL «DÍA DE LA UNIDAD ALEMANA», EL 3 DE OCTUBRE DE 1990 
; 
Revista de Derecho Político, núm. 40, 1995, pp. 215-219

\section{PALABRAS DEL CANCILLER FEDERAL, HELMUT KOHL, CON OCASIÓN DEL "DÍA DE LA UNIDAD ALEMANA", EL 3 DE OCTUBRE DE 1990}

\section{DÍA DE ALEGRÍA PARA TODOS LOS ALEMANES}

Tras más de cuarenta años de dolorosa división de nuestra patria, se convierte en realidad un sueño: el sueño de Alemania unida en una Europa en trance de unificarse. El día de la reunificación, el 3 de octubre de 1990, es un día de alegría y agradecimiento para todos los alemanes. La dictadura y la negación de la libertad, la opresión y la división se han superado por fin. Va a cumplirse lo que la Ley Fundamental nos ha requerido siempre: culminar la unidad y libertad de Alemania en libre autodeterminación, y esto ocurre sin guerra, sin violencia, en pleno acuerdo con nuestros socios y con nuestros vecinos en el Oeste y el Este.

Nuestro agradecimiento se dirige primordialmente a nuestras conciudadanas y conciudadanos de la anterior RDA. Con su valor, con su prudencia y sobre todo con su amor a la libertad nos han dado ejemplo de cómo una dictadura violenta puede ser pacíficamente superada. Esto será siempre uno de los magníficos capítulos de la historia alemana. Pero también es deber nuestro guardar memoria de las víctimas de la privación de libertad y opresión, del muro y de los vallados de alambres de espinos. Les debemos esto no sólo a ellos, sino también a las futuras generaciones, liberadas para siempre de semejante destino.

Durante los pasados doce meses los alemanes han demostrado estar inmunizados frente a la tentación de arrogancia nacionalista. Han dado muestras de madurez democrática y espíritu de vecindad. La República Federal de Alemania se ha ganado la confianza de Europa y del mundo a lo largo de más de cuarenta años de democracia estable en un Estado de Derecho. Sin semejante confianza no hubiéramos podido recuperar tan deprisa la unidad estatal de nuestra patria. 
Les debemos agradecimiento a nuestros aliados occidentales, amigos y socios, principalmente a los Estados Unidos de América, Francia y Gran Bretaña, que en los decenios pasados aseguraron nuestra libertad y asumieron su responsabilidad en Berlín. Somos y seguiremos siendo parte de nuestra comunidad de valores occidental. Nuestro agradecimiento vale asimismo respecto a los movimientos pro derechos cívicos en Polonia y Hungria - paises predecesores con sus penetrantes reformas en la política, economía y sociedad-. Pero también le debemos agradecimiento al Presidente Gorbachov, sin cuya política reformista, sin cuyo nuevo pensamiento en la política exterior, no hubieran sido posibles los cambios en Europa.

Todos sabemos que el nuevo comienzo en los cinco nuevos Laender (Estados federados) de Brandeburgo, Mecklemburgo-Pomerania, Sajonia, Sajonia-Anhalt $\vee$ Turingia plantea un reto descomunal a todo nuestro pueblo. La unificación no es asunto de días y meses, pues se extenderá a los próximos años. Requerirá trabajo duro, incluso sacrificios, hasta que se eliminen las cargas heredadas de la dictadura $y$ del desastre económico socialista. Juntos conseguiremos que los Laender de allí experimenten pronto un nuevo florecimiento. A tal efecto debemos inspirarnos en la obra de hace cuarenta años, cuando partiendo de las ruinas de nuestras ciudades destruidas empezamos a construir la República Federal de Alemania. Entonces, con valor y tenaz resolución, con laboriosidad e ingenio, con conciencia de la índole comunitaria de las tareas, las personas consiguieron crear un orden libre y democrático, eficiente $y$ socialmente justo. Ahora queremos que todo esto sea por fin realidad en toda Alemania.

El logro de esta gran tarea de configuración es de gran importancia para el futuro de Europa. Más allá de las fronteras de Alemania, que, situada en el centro de Europa, tiene más vecinos que cualquier otro país europeo; sabemos que la Alemania unida tendrá un peso especial en el entramado político y económico de la Europa del mañana. Por esto somos conscientes desde el principio de que la unidad de Alemania afecta y conmueve a todos nuestros vecinos.

Al final de un siglo que ha reportado a Europa muchas guerras, sufrimiento y penuria, queremos llegar a entendimiento y reconciliación duraderos con nuestros vecinos. Queremos participar en la construcción de la nueva Europa unida. Pues Europa es el futuro de Alemania, y ambas, la unidad alemana y la unidad europea, son dos caras de una sola medaIla. Esto ha sido confirmado de modo impresionante por los cambios del año pasado. 
La amistad entre alemanes y franceses ha sido condición previa para la construcción de la Comunidad Europea. Requisito previo de hoy: sin reconciliación y auténtica asociación entre alemanes y polacos no puede culminarse la unidad europea.

En ambas partes persisten heridas de larga curación. A muchos alemanes expulsados de su patria chica y a muchos refugiados les duele profundamente la pérdida definitiva de Silesia, del Brandeburgo Oriental, Pomerania, Prusia Occidental y Oriental y de otras comarcas al Este de los ríos Oder y Neisse, que a lo largo de siglos fueron patria chica de alemanes. Nadie puede arrogarse el derecho a privar de respeto a semejantes sentimientos, pero también debe decirse abiertamente que se habría desaprovechado la oportunidad histórica de culminar la unidad de Alemania en libertad si no se hubiera dado una clara respuesta a la cuestión de la frontera polaca occidental.

Ahora que estamos llegando ya al final del período de la posguerra, tenemos la oportunidad de iniciar una nueva fase de la historia europea, una fase en la cual la cooperación sustituye al antagonismo. $Y$ los pueblos europeos lleguen a convivir en seguridad con fronteras abiertas. Perseguimos amplia cooperación, también con la Unión Soviética. Y simultáneamente aspiramos a realizar un orden de paz estable y duradera en Europa.

El mandato de la Ley Fundamental de que los alemanes han de contribuir a la paz del mundo en una Europa unida, es a la vez mensaje del 3 de octubre de 1990. Como "Europeos Alemanes" y "Alemanes Europeos" queremos marchar juntos hacia un futuro feliz. 